\title{
e-interview
}

\section{Michéle Tansella}

Michéle Tansella is Professor of Psychiatry and Director, South-Verona Mental Health Service and Director of the Department of Medicine and Public Health, University of Verona. He trained at the University of Bari, the Institute of Psychiatry in London and the University of Verona. His main interests are in community psychiatry and service evaluation.

\section{If you were not a psychiatrist, what would you do?}

would have liked to have been an architect. I am not sure I have the right attitude and abilities, but I am fascinated by their work. In a paper published a couple of years ago I discussed the similarities between the community psychiatrist and the architect, as opposed to the similarities between the dynamic psychotherapist and the archaeologist (Tansella, M. The psychiatrist as archaeologist and architect. Advances in PsychiatricTreatment, March 2001, 7, 8182).

\section{What are your interests outside of work?}

The arts and literature, but I feel I have too little time for them. I dream to be able to read in the future, after my retirement, in 10 years time, all the books I was unable to read before and that I am still unable to read now.

\section{Who was your most influential} trainer?

Professor Michael Shepherd from whom I learned many things, related both to clinical practice and to research in mental health. I shall never forget two things: First, the importance of what he called, after Margaret Wiley, 'creative scepticism'. Shepherd used to quote Daniel Tuke, who in 1884 said: 'scepticism in the physician is the best means of arriving at the truth: faith in the patient the best means of arriving at health'. Second, the relevance, for our profession, of 'controlled enthusiasm'. Michael Shepherd, in his last interview, given to David Healy in June 1995, 6 weeks before his sudden death, said: '. . what you need is controlled enthusiasm. Without enthusiasm nothing happens. Unrestrained, Auschwitz happens. The Inquisition happens. The atomic bomb happens. So you're

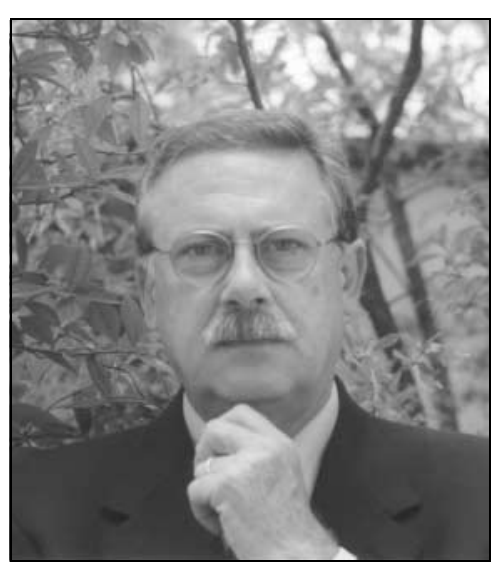

What is the most promising opportunity facing the profession? The possibility of working in closer collaboration with other professionals from social and health services, to create links and new solutions to reduce the difficulties experienced by our patients.

What is the greatest threat?

To satisfy administrators who need to cut services and save money.

What single change would substantially improve quality of care? More attention to patients' needs (as well as symptoms and disabilities) and more respect, by the central and regional governments, for the public health approach.

caught. You have to accept that this is part of the motivation, the actual mechanism of human activity, which keeps people moving, but God help them if they don't ask where is it going - on the assumption that you can control it.' These two concepts, creative scepticism and controlled enthusiasm, had a profound influence in my training and in my way of thinking

What job gave you the most useful training experience?

The training I got at the 'Mario Negri' Institute in Milan, after I finished medical school and before starting my postgraduate course in psychiatry. I did some research in psychopharmacology and I learned the 'scientific method' there.

Which book has influenced you most? The book of collected papers by Michael Shepherd Conceptual Issues in Psychological Medicine and, in quite another field The Posthumous Papers of the Pickwick Club, by Charles Dickens.

What part of your work gives you the most satisfaction?

Organising research and training for young colleagues and supporting their psychiatric careers.

What do you least enjoy?

Administration, writing letters and reports. When I need to tackle difficult problems I prefer, whenever possible, to talk on the phone instead of writing. A rather typical Italian attitude, I guess.

\section{What conflict of interest do you} encounter most often?

The pharmaceutical industry has increasing influence on training, research, the publication of scientific journals and the organisation of meetings. This is becoming a 'monopoly', and should be more balanced by adequate funding and support from independent bodies, including Foundations.

What is the most important advice you could offer to a new trainee?

To develop a critical approach to the field. Sir Aubrey Lewis valued 'incessant demand for evidence and consistent awareness of the distinction between the first and final causes'.

What single change to mental health legislation would you like to see? I can refer to the Italian legislation and I believe that we do not need any change. We need more stringent supervision by the regional governments to make sure that al services meet the required standards and provide good quality care.

What single area of psychiatric research should be given priority? Psychosocial and health service research to integrate biological research projects.

What single area of psychiatric practice is most in need of development? Adolescent psychiatry.

Dominic Fannon 